view its terms of reference need to be re-defined and some of its original functions should be formally assigned to other College bodies, which, to a considerable extent, is already the de facto position.

Meanwhile, the Committee prospers albeit deliberating mainly on issues which come to it because they do not readily fall within the terms of reference of other College bodies. It has most recently been putting its final views on the Mental Health (Amendment) Bill to the Special Standing Committee, establishing working parties on the subjects of the Court of Protection and Lord Chancellor's Visitors, and the Management of Attempted Suicide, as well as commenting on DHSS documents on In-patient Facilities for the
Mentally Ill and the Registration System for Accommodation Registered under the Residential Homes Act.

The range of subjects discussed clearly varies from those of widespread interest and controversy to trivial topics which nevertheless merit consideration, and range from lively and exciting to dull and tedious. This broad variety makes being a member of this Committee stimulating and informative. However, I consider that too wide a range of subjects reduces effectiveness and in its present role the PPC may have a limited future. I forecast that it will either be fragmented and absorbed into other College bodies or that it will thrive with more sharply defined, if more restricted, terms of reference.

\title{
Medical Visitors and the Court of Protection
}

The following guidelines (approved by Council in June 1982) are published to assist doctors who may be involved in preparing medical certificates for the Court of Protection in connection with the appointment of a receiver for a patient who is incapable of managing his affairs.

\section{Certificates of Incapacity_-Guidelines for Medical Officers}

1. Doctors should be aware that if a person owning real or personal property becomes incapable, by reason of mental disorder, of safeguarding and managing his affairs, an application should be made to the Court of Protection for the appointment of a Receiver. This procedure applies equally to those cases in which a patient has given a Power of Attorney but which ceases to be valid when the patient, by virtue of such disorder, is no longer capable of withdrawing it.

2. The Court of Protection is an office of the Supreme Court of Judicature, under the direction of a Master, assisted by a Deputy Master and other nominated officers known as Assistant Masters. The Court's existence in some form is considered to have arisen in the reign of Edward I; its jurisdiction and procedures are now governed by the Mental Health Act 1959 and the Court of Protection Rules 1982. The Court's primary function is to safeguard the interests of a patient by providing for his maintenance and that of his family and dependants and for the general management of his property and affairs. The latter will include, for example, authorizing the Receiver to receive rents, dividends, pensions or other income arising, sign documents and care for or possibly sell the patient's house (if he is no longer able to reside there) and, of course, general oversight by the Court in all these and many other matters.

3. An application to the Court of Protection for the appointment of a Receiver must be supported by a medical certificate stating that, in the doctor's opinion, the patient is incapable of managing and administering his property and affairs by virtue of mental disorder (as defined in Section 4 of the Mental Health Act 1959).

4. Criteria for assessing incapacity are not identical with those for assessing the need for compulsory admission to hospital. The fact that a person is suffering from mental disorder within the meaning of the Mental Health Act 1959, whether living in the community or resident in hospital, detained or informal, is not of itself evidence of incapacity to manage his affairs. On the other hand, a person may be so incapable and yet not be liable to compulsory admission to hospital.

5. The certifying doctor is usually the person's general practitioner or a consultant, but any doctor who has examined the patient may give a certificate. He does not have to be approved under Section 28 of the Mental Health Act 1959 as having special experience in the diagnosis or treatment of mental disorder.

6. The certificate is given on form C.P. 3 which requires the doctor to state in paragraph 3 the grounds on which he bases his opinion of incapacity. It is this part of the certificate which appears to give the doctor the most difficulty. What is required is not merely a diagnosis (although this may be included) but a simple statement giving clear evidence of incapacity which an intelligent lay person could understand, e.g. reference to defect of short-term memory, of spatial and temporal orientation or of reasoning ability, or to reckless spending (sometimes periodic as in mania) without regard for the future, or evidence of vulnerability to exploitation.

7. In many cases of senile dementia, severe brain damage, acute or chronic psychiatric disorder and severe mental 
handicap the assessment of incapacity should present little difficulty. Cases of alcoholism, functional and personality disorders may present more difficulty, and assessment may depend on the individual doctor's interpretation of mental disorder. However, it appears that the Court tends towards the view that these conditions render a person liable to its jurisdiction where there appears a real danger that they will lead to dissipation of considerable capital assets.

8. The Court's procedure requires that a patient is served with notice of the proposed proceedings for the appointment of a Receiver and this is a task often undertaken by the certifying doctor. The Court attaches considerable importance to such service since the patient may have an objection, though irrational, to the appointment of a particular person or may, even unwittingly, contribute information of assistance to the Court. The Court has power under its Rules to dispense with service where it is satisfied (a) that the patient is incapable of understanding the notice, (b) that service would be injurious to his health, or (c) that for any other reason service ought to be dispensed with. However, the Court is reluctant to dispense with service as it is considered that a person has a right to know-or, at least be given an opportunity to understand-if the management of his affairs is to be taken out of his hands and thereafter dealt with by someone on his behalf; if he has no understanding at all, then service cannot affect him adversely and a patient who has sufficient insight to appreciate the significance of the Court's proceedings may need reassurance that they are for his benefit.

9. The prime responsibility for a patient's welfare rests with his family (of which the Receiver is usually a member) and his general practitioner or a consultant. The concern of the Lord Chancellor's Medical Visitors for a patient's welfare stems from the Court's responsibility for the management of the patient's property and affairs. The Visitors' prime function is to inform the Court so that it may meet its responsibilities. Due to the burden of work falling on them, the Medical Visitors visit only those patients who are cared for in their own homes or in nursing homes-and in many cases, upon one occasion only. When a patient is in hospital and likely to require such continuing type of care, it is regarded as the consultant's responsibility to see that the Court is informed, for example, where the patient could benefit from private care or from a course of treatment or some physical aid which may be provided if private funds are available.

\section{Symposium on Research into the Health and Social Consequences of Unemployment}

There has been growing concern among members of the College about the possible effects on health of rising unemployment; the Research Committee has been considering this and in particular has been exploring the possibility of encouraging further research in this field. Members of the Committee felt that on the whole general practitioners would be likely to see those affected in far greater numbers than psychiatrists. The Research Committee therefore organized a small symposium and invited representatives of the Social and Community Psychiatry Section and of the Research Division of the Royal College of General Practitioners to join it. The symposium was held at the College on 15 October 1982.

Following an introduction by the Chairman of the Research Committee, Professor Andrew Sims, Dr Sheila Mann gave a brief account of some previous work in this field, and the conclusions that might be drawn. Professor David Metcalfe (Department of General Practice, University of Manchester) then described a large study of urban primary care which he is presently undertaking. It has been possible to look at some aspects of unemployed people from this study, although it was not designed to do so.
A lively discussion followed with all participants taking part. Although the difficulties of undertaking research in this field were acknowledged, and the importance of defining parameters accurately stressed, there was agreement that there was considerable need to undertake further research and great enthusiasm to explore how to do so further. A number of approaches were suggested in greater or lesser detail and at the conclusion, it was agreed to form a small working group with representation from those at the symposium with the intention of examining further the possibility of research in this field.

We are aware that many initiatives have been started in recent months and that there is no central pool of information on these. Members of the working group would therefore be pleased to hear from College members who have or are undertaking work in this field, or who know of other projects recently set up, or who have useful suggestions that could be considered. Please send any such comments in writing to the Secretary of the Research Committee.

SheILA A. ManN

Secretary, Research Committee 